\title{
Comparative efficacy of levofloxacin and ceftriaxone in the treatment of community acquired pneumonia in children
}

\author{
Mujibul Hoque*, Mohammad Nuruzzaman, Md. Abdul Malik \\ Department of Pediatrics, Sylhet MAG Osmani Medical College, Sylhet, Bangladesh \\ Email: ${ }^{*}$ drmujib@ymail.com
}

Received 26 May 2013; revised 28 June 2013; accepted 5 July 2013

Copyright (C) 2013 Mujibul Hoque et al. This is an open access article distributed under the Creative Commons Attribution License, which permits unrestricted use, distribution, and reproduction in any medium, provided the original work is properly cited.

\begin{abstract}
Pneumonia is a common cause of mortality and morbidity in under-5 children throughout the world. Globally an estimated 156 million new episodes of pneumonia occur each year in children and 2 million children die from pneumonia each year which is 20 percent of all deaths of children under five years old. Ceftriaxone is a commonly used drug for empiric treatment of community acquired pneumonia (CAP) in children. Levofloxacin may be an adequate option for empiric therapy in treatment of CAP in children because it gives the broad spectrum activity against both bacterial and atypical pathogens causing CAP and studies suggest that it can be safely used in children. This open labeled, randomized, comparative clinical trial was carried out in the Department of Pediatrics, Sylhet MAG Osmani Medical College Hospital, Bangladesh during January, 2011 \& December, 2012 to compare the efficacy of levofloxacin and ceftriaxone in the treatment CAP in children. A total 70 cases of CAP were enrolled. 35 cases were allocated to levofloxacin group and another 35 cases to ceftriaxone group. At first the study cases were selected by systematic random sampling. Group allocation to either levofloxacin or ceftriaxone group was done by lottery method. Total duration for receiving study drugs was seven days. Dose of levofloxacin was $10 \mathrm{mg} / \mathrm{kg} / \mathrm{day}$ children $\geq 5$ years, where as it was 10 $\mathrm{mg} / \mathrm{kg} 12$ hourly in 6 months to $<5$ years age groups. Dose of ceftriaxone was $75 \mathrm{mg} / \mathrm{kg} / \mathrm{day}$. Response to treatment was assessed initially after 3 days and also after 7 days by clinical symptoms and signs. Clinical cure rate was determined by disappearance of the clinical signs and symptoms of pneumonia and resolution of radiological findings reported at admission. Clinical responses were categorized as cured and treatment failure. $91.43 \%$ cases were cured in levofloxacin

${ }^{*}$ Corresponding author.
\end{abstract}

group, whereas cure rate of ceftriaxone group was $68.57 \%$ which was statistically significant $(p=0.0168)$. Adverse effects of levofloxacin were found as skin rash in 1 case and vomiting in 2 cases whereas skin rash was found in 1 case in ceftriaxone group. So it can be concluded that levofloxacin is more effective than ceftriaxone in the treatment of CAP in children.

Keywords: Community Acquired Pneumonia; Ceftriaxone; Levofloxacin

\section{INTRODUCTION}

Pneumonia may be defined as an inflammation of the parenchyma of the lungs [1]. Of the different types, community acquired pneumonia (CAP) is the most common and important from public health point of view. Pneumonia is a substantial cause of morbidity and mortality in children throughout the world, particularly among children $<5$ years of age with an estimated 156 million new episodes occur each year and most of these occur in India (43 million), China (21 million), Pakistan (10 million) and Bangladesh, Indonesia and Nigeria (6 million each) [2]. About 2 million children worldwide die from pneumonia each year which is 20 percent of all deaths of children under five years old. These occur mainly (about $75 \%$ ) in the African and South-East Asian regions [3]. Bangladesh has the fifth-highest rate of pneumonia in the world, with an estimated 6 million cases and 50,000 deaths annually among children under five [3]. The incidence of pneumonia among children age $<5$ years who live in the rural area is 0.23 episodes per child-year and urban areas is 0.56 episodes per child-year in Bangladesh [4]. Antibiotics are the mainstay in the treatment of CAP. Empirically used common antibiotics for CAP in children are cotrimoxazole, penicillins, macrolides, aminoglycosides and cephalosporins. Some recent study suggested that floruquinolons specially levofloxacin can 
be effectively used in the treatment of CAP in children [5-7].

Due to its unique efficacy and safety ceftriaxone is widely used in the treatment of CAP worldwide. But resistant strain of Pneumococci $(6 \%)$ which is the most common organism causing CAP is noted worldwide [8]. Levofloxacin may be an adequate option for empiric therapy in treatment of CAP in children because it gives the broad spectrum activity against both bacterial and atypical pathogens causing CAP and studies suggest that it can be safely used in children [9]. This study was designed to compare the efficacy of levofloxacin and ceftriaxone in the treatment of CAP in children.

\section{PATIENTS AND METHODS}

\subsection{Selection of Patients}

This open labeled randomized comparative clinical trial was conducted in the Department of Pediatrics, Sylhet MAG Osmani Medical College Hospital, Bangladesh from January 2011 to December 2012. Children aged 1 12 years were included in the study. CAP was diagnosed by the following criteria: 1) Signs and symptoms of pneumonia including at least 2 of the following: (a) fever (axiliary or oral temperature $>100.4^{\circ} \mathrm{F}$ ); (b) cough for less than 21 days; (c) chest pain; (d) shortness of breath; (e) physical findings of consolidation and (f) white blood cell count $>15000 /$ ul or $<5000 /$ ul; 2) Chest x-ray showing evidence of lung infection (pulmonary opacity, pneumatocele). Hospital acquired pneumonia; suppurative lung disease and pleural effusion were excluded from the study. Children with CAP receiving ceftriaxone and levofloxacin before enrollment were also excluded from the study. After diagnosis as CAP children were enrolled in the study by systematic random sampling. Every $2^{\text {nd }}$ case satisfying the inclusion and exclusion criteria were enrolled in the study. A total of 70 cases of CAP were enrolled. 35 cases were allocated to each group. Group allocation of the $1^{\text {st }}$ case to levofloxacin group was done by lottery method. Then every consecutive patient was allocated to alternate group.

\subsection{Intervention}

Total 35 children received levofloxacin and another 35 received ceftriaxone. Dose of levofloxacin was $10 \mathrm{mg}$ / $\mathrm{kg} /$ day children $\geq 5$ years, where as it was $10 \mathrm{mg} / \mathrm{kg} 12$ hourly in $<5$ years age groups [10,11]. Dose of ceftriaxone was $75 \mathrm{mg} / \mathrm{kg} /$ day [11]. All the enrolled patients received supportive care for CAP such as oxygen inhalation, maintenance of temperature, oropharyngeal suction and nutrition. Total duration for receiving study drugs were seven days. Regular follow up was given during study period. Response to treatment was assessed initially after 3 days and also after 7 days by clinical symp- toms and signs (fever, cough, shortness of breath, chest pain, rales on auscultation, dullness to percussion, egophony). Additional chest $\mathrm{x}$-ray was done during assessment at $7^{\text {th }}$ days. Clinical responses were categorized as cured and treatment failure.

If no response occurred after 3 days the respective antibiotic was stopped and another antibiotic suitable for CAP outside the study were started and that case was labeled as treatment failure.

Clinical cure was determined by disappearance of the clinical signs and symptoms of pneumonia and resolution of radiological findings reported at admission. If there was no resolution of clinical signs and symptoms and radiological findings the case was labeled as treatment failure (Figure 1).

\subsection{Data Collection and Statistical Analysis}

Data were collected by a preformed and pretested structured questionnaire. Analysis of age variation was done by unpaired $\boldsymbol{t}$ test. Analysis of sex difference and comparison of cure rate between two groups was done by $x^{2}$ test. A p-value of $<0.05$ were considered as significant. Data were analyzed by using SPSS version 17 .

\subsection{Ethical Consideration}

Informed written consent was taken from parents or legal guardian. Beforehand ethical permission was taken from the ethical committee of Sylhet MAG Osmani Medical College, Sylhet, Bangladesh.

\section{RESULT}

A total 35 cases were allocated to levofloxacin group and another 35 in ceftriaxone group. The mean age of the patients in both groups was almost identical (40.7143 \pm

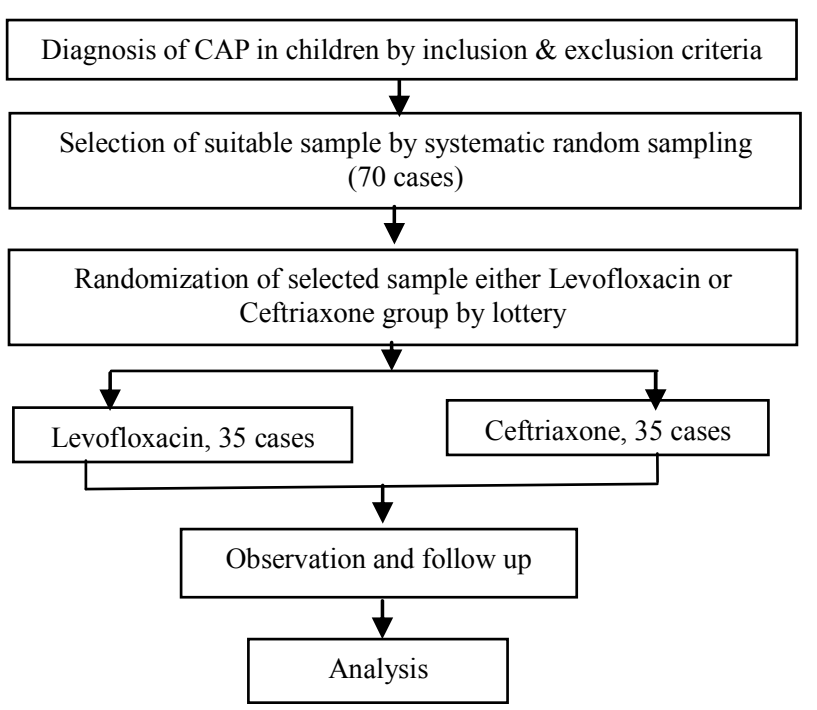

Figure 1. Flow chart of randomization \& intervention. 
32.73474 months vs. $36.00 \pm 33.6181$ months, $\mathrm{p}=0.669$ ). The sex of the patients in levofloxacin group and ceftriaxone group did not show any statistically significant difference $(p=0.6913)($ Shown in Table 1).

Out of 35 patients $32(91.43 \%)$ were cured with levofloxacin, 3 patients $(8.57 \%)$ were not cured. In the ceftriaxone group $24(68.57 \%)$ children were cured and 11 patients $(31.43 \%)$ were not cured. This difference was statistically significant $(\mathrm{p}=0.0168)$ (Shown in Table 2).

Both levofloxacin and ceftriaxone showed no major adverse effects. Adverse effects of levofloxacin were found as skin rash in $2(5.7 \%)$ cases and vomiting in 1 $(2.85 \%)$ case. Skin rashes were transient in nature. No arthropathy was observed in this group. In ceftriaxone group skin rash was found in $1(2.85 \%)$ case. Adverse effects of levofloxacin and ceftriaxone are shown in Table 3.

\section{DISCUSSION}

Pneumonia is a one of the most common cause of childhood morbidity mortality. Effective and resource compatible antimicrobial management is one of the fundamental aspects of the treatment of CAP.

In the present study age and sex characteristics of levofloxacin and ceftriaxone groups were almost identical $(40.7143 \pm 32.73474$ months versus $36.00 \pm 33.6181$ months, $\mathrm{p}=0.669$ and in case of sex, $\mathrm{p}=0.203$ ).

The present study revealed that cure rate of levoflox-

Table 1. Age and sex characteristics of CAP patients.

\begin{tabular}{cccc}
\hline $\begin{array}{c}\text { Demographic } \\
\text { character }\end{array}$ & $\begin{array}{c}\text { Levofloxacin } \\
\text { group }(\mathbf{n}=35)\end{array}$ & $\begin{array}{c}\text { Ceftriaxone } \\
\text { group }(\mathbf{n}=35)\end{array}$ & p-value \\
\hline $\begin{array}{c}\text { Age in months } \\
\text { (Mean } \pm \text { SD) }\end{array}$ & $40.7143 \pm 32.73474$ & $36.00 \pm 33.61810$ & 0.669 \\
Sex & & & \\
Male & $21(60 \%)$ & $26(74.28 \%)$ & 0.6913 \\
Female & $14(40 \%)$ & $09(25.71 \%)$ & \\
\hline
\end{tabular}

Table 2. Comparison of levofloxacin and ceftriaxone in the treatment of CAP.

\begin{tabular}{cccc}
\hline Parameter & $\begin{array}{c}\text { Levofloxacin } \\
\text { group }(\mathbf{n}=35)\end{array}$ & $\begin{array}{c}\text { Ceftriaxone } \\
\text { group }(\mathbf{n}=35)\end{array}$ & p-value \\
\hline Cured & $32(91.40 \%)$ & $24(68.57)$ & 0.0168 \\
Not cured & $03(8.57 \%)$ & $11(31.43 \%)$ & \\
\hline
\end{tabular}

Table 3. Adverse effects of levofloxacin and ceftriaxone.

\begin{tabular}{lcc}
\hline Adverse effects & Levofloxacin & Ceftriaxone \\
\hline Vomiting & $1(2.85 \%)$ & 0 \\
Rash & $2(5.7 \%)$ & $1(2.85 \%)$ \\
Arthopathy & 0 & 0 \\
Headache & 0 & 0 \\
Photosensitivity & 0 & 0 \\
\hline
\end{tabular}

acin group was $91.43 \%$, whereas cure rate of ceftriaxone group was $68.57 \%(\mathrm{p}=0.03647)$. Bradley et al. [5] in their comparative study of levofloxacin in the treatment of children with community-acquired pneumonia showed that cure rate of levofloxacin was $94.3 \%$ whereas cure rate of comparator group $(0.5$ to $<5$ years: amoxicillin/ clavulanate or ceftriaxone; $>$ or $=5$ years: clarithromycin or ceftriaxone with clarithromycin or erythromycin lactobinate) was $94 \%$. File et al. [12] in their comparative study of intravenous and/or oral levofloxacin $(500 \mathrm{mg}$ once daily) or the comparative agents, parenteral ceftriaxone (1 to $2 \mathrm{~g}$ once to twice daily) and/or oral cefuroxime axetil (500 $\mathrm{mg}$ twice daily) in treatment of adults with community-acquired pneumonia showed that clinical success rate of levofloxacin (96\%) is superior to ceftriaxone and/or cefuroxime axetil $(90 \%)$ in the management of adult with CAP. Cure rate of levofloxacin in these mentioned studies support the present study. But cure rate of ceftriaxone is much less in the present study. Less cure rate of ceftriaxone in present study may be due to its resistance as a result of indiscriminate use of ceftriaxone at the community level of Bangladesh.

Adverse effect of levofloxacin was found as skin rash in $2(5.7 \%)$ cases and vomiting was found in $1(2.85 \%)$ case. Skin rashes were transient in nature. In ceftriaxone group skin rash was found in 1 case $(2.85 \%)$. There was no need to discontinue treatment in both groups. In the comparative study of Bradly et al. [5], adverse events leading to treatment discontinuation occurred in $2 \%$ levofloxacin-treated and 1\% comparator-treated children. No single type of treatment-limiting adverse event occurred in more than $1 \%$ of children. In the levofloxacin group, the most frequent category of adverse events that were treatment-limiting involved the gastrointestinal system (1\%). Levofloxacin was as well tolerated as standard of care antibiotics for the treatment of CAP. Congress report from the $41^{\text {st }}$ inter-science conference on antimicrobial agents and chemotherapy Chicago, IL, USA, states levofloxacin has no serious adverse reaction in children [13].

As the diagnosis of CAP was not confirmed by bacteriological study, microbial cure rate was not determined in the present study.

\section{CONCLUSION}

Levofloxacin was more effective than ceftriaxone in the treatment of CAP in children. Large scale study may further strengthen its use in the treatment of CAP in children.

\section{REFERENCES}

[1] Sectish, C.T. and Prober, C.G. (2007) Pneumonia. In: Kliegman, R.M., Behrman, R.E., Jenson, H.B. and Stan- 
ton, B.F., Eds., Nelson Text Book of Paediatrics, Saunders, New Delhi, 1795-1798.

[2] Kabra, S.K., Lodha, R. and Pandy, R.M. (2010) Antibiotic for community acquired pneumonia in children. Cochrane Database of Systematic Reviews, 17. doi:10.1002/14651858.CD004874.pub3

[3] UNICEF/WHO (2013) Pneumonia: The forgotten killer of children.

http://www.who.int/maternal_child_adolescent/document s/9280640489/en/

[4] Naheed, A., Saha, S.K., Breiman, R.F., Khatun, F., Brooks, W.A., Arifeen, S.E., et al. (2009) Multihospital surveillance of pneumonia burden among children aged $<5$ years hospitalized for pneumonia in Bangladesh. CID, 48, S82S89. doi:10.1086/596485

[5] Bradley, J.S., Arguedas, A., Blumer, J.L., Saéz-Llorens, X., Melkote, R. and Noel, G.J. (2007) Comparative study of levofloxacin in the treatment of children with community-acquired pneumonia. The Pediatric Infectious Disease Journal, 26, 868-878. doi:10.1097/INF.0b013e3180cbd2c7

[6] Chein, S., Wells, T.G., Blumer, J.L., Kearnset, G.L., Bradly, J.S., Bocchini, J.A., et al. (2005) Levofloxacin pharmacokinetic in children. The Journal of Clinical Pharmacology, 45, 153-160. doi:10.1177/0091270004271944

[7] Rang, H.P., Dale, M.M., Ritter, J.M. and Flower, R.J. (2008) Rang and dale's pharmacology. Churchill Livingstone Elsevier, New York, 660-678.

[8] Pallares, R., Linares, J., Vadillo, M., Cabellos, C., Manresa, F., Viladrich, P.F., Martin, R. and Gudiol, F. (1995)
Penicillin and cephalosporin and mortality from severe pneumococcal pneumonia in Barcelona. The New England Journal of Medicine, 333, 474-480. doi:10.1056/NEJM199508243330802

[9] WHO (2011) Fluroquinolones use in paediatrics: Focus on safety and place in therapy. 18th Expart Committee on the Selection and Use of Essential Medicines, Gneva, 113.

[10] Bradly, J.A. (2013) Multicentre, randomized, open-label, comparative study to compare the efficacy and safety of levofloxacin and standard of care therapy in the treatment of children with community-acquired pneumonia in the hospitalized or outpatient setting. http://filehosting.pharmacon.com

[11] Chambers, H.F. and Deck, D.H. (2009) Sulfonamides, trimethoprim \& quinolones. In: Katzung, B.G., Master, S.B. and Trevor, J.A., Eds., Basic and Clinical Pharmacology, Prentice-Hall International Inc., New Delhi, 815-822.

[12] File, J.R., Segreti, J., Dunbar, L., Player, R., Kohler, R., Williams, R.R., et al. (1997) A multicentre, randomized study comparing the efficacy and safety of intravenous and/or oral levofloxacin versus ceftriaxone and/or cefuroxime axetil in treatment of adults with community-acquired pneumonia. Antimicrob Agents and Chemother, 41, 1965-1972.

[13] Prescot, L.M. (2002) Highlights of the 41st interscience conference on antimicrobial agents and chemotherapy. Pharmacy \& Therapeutics, 77, 143-146. 